\title{
Mandala making to foster understanding of theoretical concepts in nursing education: Stress and coping
}

\author{
Jennifer L. Lapum ${ }^{*}$ Karen Owusu, Andy N. Tan, Simran Rattan, Phung P.N. Nguyen, Einav T. Simoni, Charlotte T. \\ Lee \\ Daphne Cockwell School of Nursing, Ryerson University, Toronto, Canada
}

Received: November 23, 2016

DOI: $10.5430 /$ jnep.v7n7p22
Accepted: February 3, 2017

Online Published: February 13, 2017

URL: http://dx.doi.org/10.5430/jnep.v7n7p22

\begin{abstract}
Opportunities for reflection upon theoretical concepts are a pedagogical necessity in nursing education. Arts-based teachinglearning methods, such as mandala making, can prompt narrative reflection and self-awareness. In this article, we discuss a teaching-learning activity that involved mandala making to facilitate nursing students' theoretical understanding of health- and illness-related concepts specific to stress and coping. We begin by describing the activity followed by narrative reflections and mandalas from five students. We then share lessons learned in the context of the literature. We suggest that aesthetic narrative probes strengthen the mandala making process and foster deep reflection on theoretical concepts in nursing education.
\end{abstract}

Key Words: Nursing theory, Nursing education, Mandala making, Arts-based pedagogy, Narratives

\section{INTRODUCTION}

A theoretical understanding of health- and illness-related concepts is vital so that nurses are positioned to grasp the full meaning of a situation and care for the client as a whole person. The abstract nature of theory can make it challenging for nursing and other health care students to understand and recognize its significance. At the outset, it is paramount to reflect upon theoretical concepts as a means to deliberately view and examine phenomena. ${ }^{[1]}$ Personal narratives and professional reflection on concepts can provide theoretical insight and foster students' learning journey. Yancey ${ }^{[2]}$ remarks that nurse educators must "bear witness to the journey of students as they discover new knowledge, co-create new understandings, and reveal their own wisdom" (p. 274). The provision of opportunities to reflect and journey with these theoretical concepts is thus a pedagogical necessity in nursing education.
Reflection can be fostered through narrative and arts-based teaching-learning methods. Narrative reflection, commonly used in nursing and part of narrative medicine, encompasses the sharing of one's experiences through storytelling, ${ }^{[3]}$ while arts-based pedagogy involves the integration of creative and arts media (e.g., poetry, dance, visual images, film) into the teaching-learning approach. ${ }^{[4-7]}$ These creative teachinglearning approaches have been used across health care disciplines to enhance learner engagement and self-awareness as well as to facilitate an understanding of theoretical and substantive content. ${ }^{[5-8]}$ The creative use of mandala making is an art form that has been used in nursing to foster selfawareness and facilitate student learning. ${ }^{[7,9,10]}$ Mandalas are circular shapes or concentric designs ${ }^{[11,12]}$ that can be traced back to Buddhist and Indian tradition. ${ }^{[7,10]}$ Mandalas can be designed with varying symbols and patterns as well as colors and tones to represent an experience, reflection,

\footnotetext{
*Correspondence: Jennifer L. Lapum; Email: jlapum@ ryerson.ca; Address: Daphne Cockwell School of Nursing, Ryerson University, Toronto,
} Canada. 
or idea. Mandalas often incorporate symbolic patterns and content that are related to and constructed around a principal point. ${ }^{[11]}$

In this article, we discuss a teaching-learning activity that involved mandala making to facilitate students' theoretical understanding of the concepts of stress and coping. Since this was novel activity, the teacher (i.e. the first author) who developed and implemented this activity invited interested students to discuss the process and pedagogical impact of this activity. These extra-curricular discussions led to a collective reflection on the pedagogy and the collaborative authorship of this article. We begin this article by describing the activity, followed by five students' reflections and mandalas related to journeying deeper into a theoretical understanding of these concepts. Last, we share lessons learned coupled with the existing literature.

\section{LEARNING ACTIVITY DESCRIPTION}

The first author developed this activity for an undergraduate course focused on the theoretical examination of health- and illness-related concepts. The course was taken by second year undergraduate nursing students who were enrolled in a four-year Baccalaureate Nursing program. The activity was implemented across multiple course sections with over 200 students. Alongside required course readings and a brief lecture related to the concepts of stress and coping, both activities began with an individual narrative reflection followed by mandala making and a discussion afterwards (time 45 to 60 minutes). Instructional design of mandalas was not provided to students. They were told that although the creation of mandalas often has specific design instructions and starting points, the instructions for this activity were minimal. On a lecture slide, the facilitator shared generally what a mandala was and provided a diverse sample of mandala examples that ranged from simple to complex in design.

The class activity began with the facilitator asking students to close their eyes or put their head down on the table. Students were asked to take three big breaths in through their nose and slowly out through their mouth as a way to relax and focus their attention. Students were asked to not speak to others during their reflection. Aesthetic narrative prompts were slowly voiced to students followed by time to write and then additional prompts. The aesthethic prompts were composed by the teacher so that students drew upon a multitude of senses as they reflected on their experiences of stress and coping. One piece of A4 size paper (approximately 8 inches $\times 11$ inches) and a large selection of crayons, colored pencils, and markers were provided. Small group and large class discussion followed the mandala making in which students were asked to share their reflections and creations. They

Published by Sciedu Press were told that they did not need to provide details about their experience unless they felt comfortable in doing so. The large class discussion focused on what it was like to reflect on the concepts and create a mandala that captured their reflections. Each activity for stress and coping was slightly different as detailed next.

\subsection{Stress activity}

The aesthetic narrative prompts for stress were: Think about a personal experience that you found stressful and that is important to you. What was that experience like? What/who was involved? Why was it stressful? Students were then asked to open their eyes and start writing about this experience. Additional prompts were: How did the stress feel? What did you hear? What did you see? If you were to draw a picture of this experience, what would it look like? What colors would you use and why? If there was music playing during this experience, what would it sound like and why? Students were asked to draw a large circle on the paper provided and had 15 minutes to design and create a mandala based on their reflection. After students had completed their mandalas, the facilitator then asked them to write a paragraph on the back of the paper about their mandala and consider: What is the story behind your mandala? How does it reflect the concept of stress? Students were encouraged to draw upon the literature.

\subsection{Coping activity}

The aesthetic narrative prompts for coping were: Place your mandala of stress on your desk. Reflect back on the significant personal experience of stress that you reflected upon as well as the mandala that you drew. Then, think about and begin writing about how you coped with this experience. Additional prompts were: What did the coping feel like? Look like? Sound like? If you were to draw a picture of this experience in terms of how you coped, what would it look like? What colors would you use and why? If there was music playing during this experience as you attempted to cope, what would it sound like and why? Students were again provided a piece of paper and had 15 minutes to create a mandala based on their narrative reflection of coping. They were then asked them to write a paragraph on the back of the paper about their mandala and consider: What is the story behind your Mandala? How does it reflect the concept of coping? Students were encouraged to again draw upon the literature.

\section{MANDAlas ANd NaRRATives}

As part of an extracurricular activity, interested students were asked to volunteer to further share their reflections and mandals. This extracurricular activity led to this discussion paper. 
In this section, we provide intimate and first-person narrative reflections and mandalas created by five students. We begin by sharing the mandalas and reflections related to stress followed by coping.

\subsection{Student One}

"I felt stressed and anxious as I cautiously waited for the thin veil of peace that remained to finally come undone as tensions rose in my home. I also felt a sense of imbalance, unsure of whether confrontation or dismissal would be the route used to find a resolution. Along with the sense of imbalance came an uncertainty which fueled my stress. My mandala (see Figure 1) is an expression of the emotions I experienced as the tension climaxed. A pink flower, at the centre of my mandala, represents the calm I struggled to hold onto as the stress of the situation heightened. Around the flower, I drew vines in a spiral shape to display the slow but dedicated progression of events which led me to feel a lack of control as the tension reached a breaking point. The vines in my mandala wind into the centre, almost reaching into the flower as if to hold it captive; this part signifies the peace being abruptly taken away. I felt trapped, powerless, and helpless. I wanted to know the right words to say to de-escalate the tension, but I could not find them. I am used to being level-headed, able to solve the problem, but in this case, I saw no solution. I yearned for peace to return and balance to be restored."

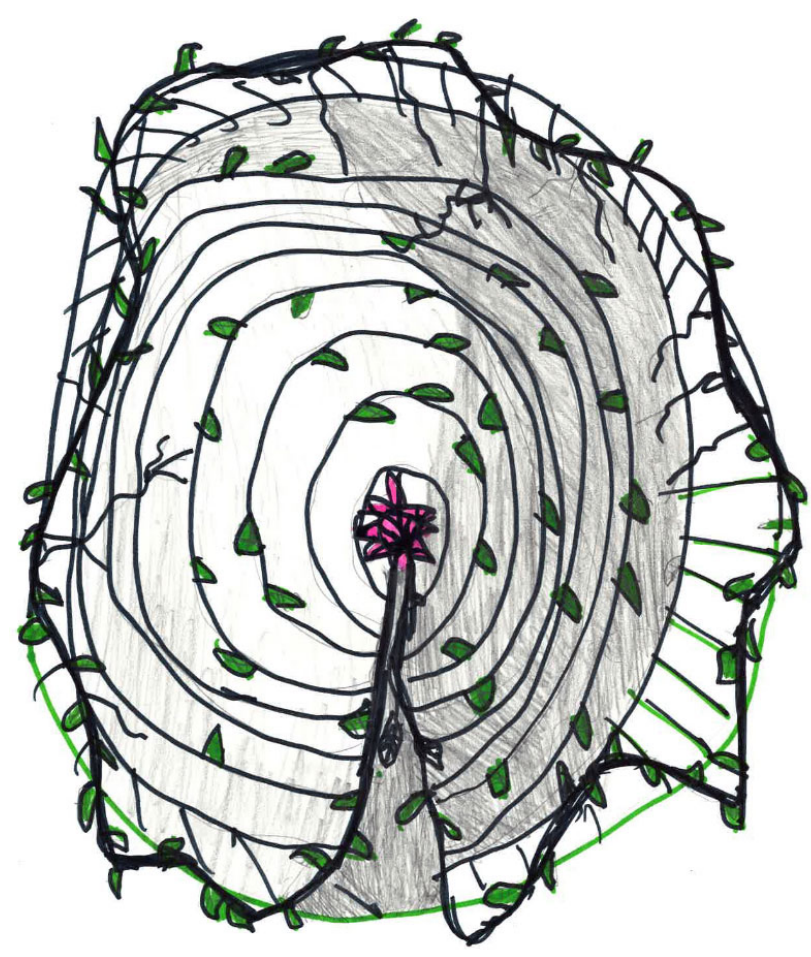

Figure 1. The breaking point
"I stepped outside alone, closing the door behind me to quiet the noise. It was night and there were no sounds, only silence. I felt still. Coping by this means allowed an air of calmness, and for a moment, I finally felt a bit of peace. I drew my mandala for coping (see Figure 2) with a big tree in the centre and its roots reaching deep into the ground with the sky shaded dark to represent the stillness and the peace I experienced being outside at night in isolation from the situation. There lies a serenity within the darkness that helped to relieve some of the anxiety. The tree symbolizes strength, which involved allowing myself to feel angry and somber, while at the same time not letting these emotions consume me. In a way I was able to find a common ground between tranquility and turbulence which served to give me back some of the control I felt I had lost. The roots from the tree deepen representing my search for balance and stability. Trees also tend to represent growth and a positive future, and signified my use of hope to help me cope. I hoped that in the end everything would work out and I had faith that this was something my family and I could overcome as we had done before. In coping with the stressor, I was able to come to terms with the fact that I did not have all the answers I needed to resolve the issue at that moment and that was okay. I still had hope, and I allowed myself to feel the stress but at the same time I was able to find peace knowing that at some point the issue would be mended."

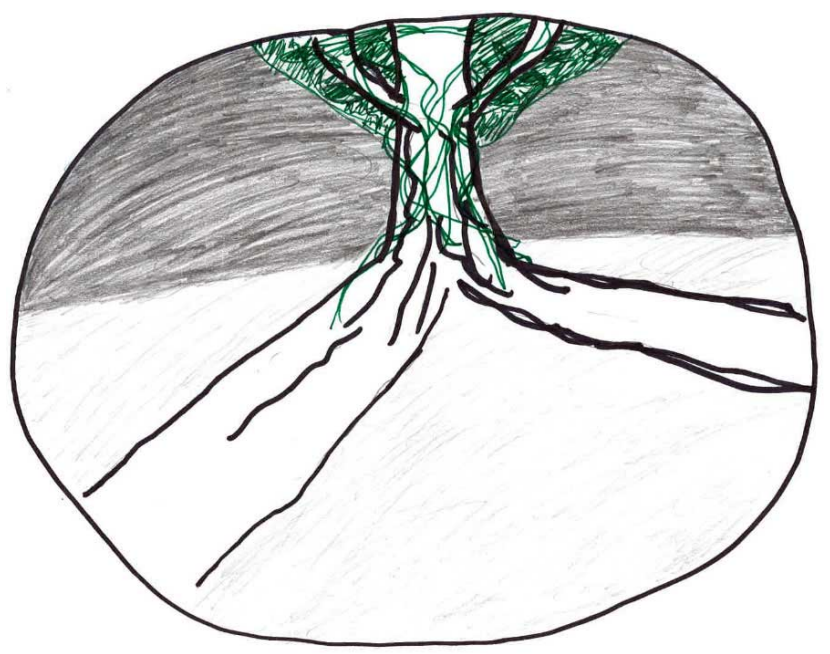

Figure 2. Strength and serenity

\subsection{Student Two}

"My life was oversaturated with responsibilities during my last year of high school. The astounding expectation placed upon myself in excelling at multiple facets of my life began to impede my ability to effectively function as a student, athlete, and individual. The irregular shaped cracks in my mandala of stress (see Figure 3) literally and figuratively 
represent my experience of a 'breakdown'. Similar to cracking pavement, my internal integrity was no longer whole as I was experiencing exceptional disruption of my physical, emotional, and psychological well-being. The black color utilized in the cracks represents the lonely isolation I experienced during my time of stress. The experience of isolation did not occur due to the lack of human interaction, rather, isolation manifested because I experienced my stress in complete silence without recognition from others. The red, gorging blood vessels in my mandala adds a humanistic aspect to my experience of stress as I, a human being with emotions and sensations, endured the suffering; this also symbolically represents the activation of the sympathetic nervous system that occurs with stress. The black cracks in conjunction with the red blood vessels depicted my experience as my stress began to break my body down in remote isolation."

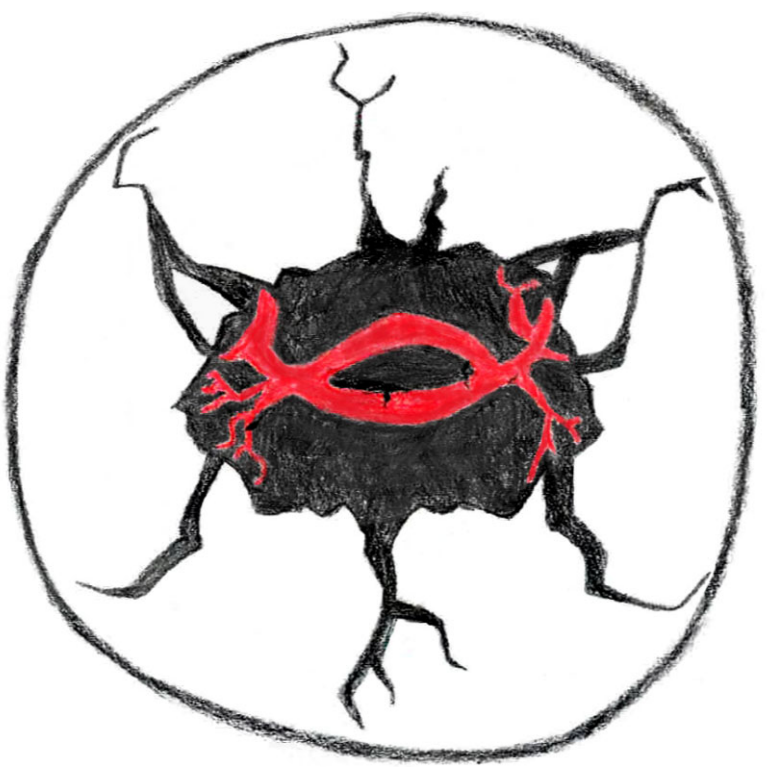

Figure 3. A breakdown

"As I experienced this time of stress in isolation, I pushed through my usual introverted behaviours and timidly shared my experience with a teacher who empathetically listened to my concerns and therapeutically shared her similar experiences. In addition to her compassionate social support and presence, my teacher's sharing of her personal anecdotes of stress resonated with me as I felt she related to my experiences and could understand. In my mandala of coping (see Figure 4), the outer intertwined lines pictorially represent the interdependence between myself and my social support systems that provided me with the multidimensional support I needed to cope. Once the social support in my life had been established, I was able to figuratively reorganize my life in a structured manner as various components could easily

Published by Sciedu Press be pieced back together, quite similar to puzzle pieces. The numerous yet important puzzle pieces symbolize the essential aspects of my life such as academics, athletics, family, health, and love. As displayed in the mandala, these puzzle pieces fit seamlessly with one another due to the presence of a structured social support system that helped me cope and piece together the complicated intricacies of my life."

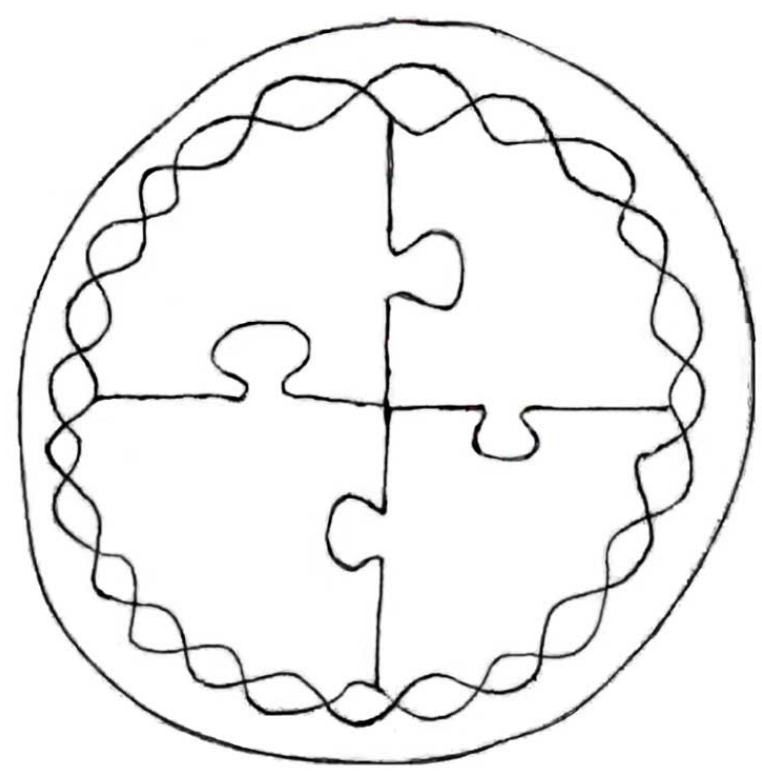

Figure 4. Puzzle pieces

\subsection{Student Three}

"My mandala (see Figure 5) represents stress in a colorful way because I choose to look at life through a positive perspective. The mandala border is surrounded by a 24-hour clock and the numbers are restricted to the outside because time is a fixed entity which cannot be changed. I find this stressful because I do not have unlimited time to complete my day-to-day responsibilities. However, I do have control over how I use the time I have in a day. For me, stress functions as a driving force that motivates me to manage my tasks and balance my professional and personal life. I placed an alarm clock at the top of the mandala to represent how my positive outlook on stress is associated with time and deadlines. The inner area of my mandala shows that I attempt to identify the stressor, I attempt to organize how I can overcome the situation, and then I act to eliminate stress while keeping an optimistic outlook. The colorful patterns and myriad of designs demonstrate chaos, but also my ability to manage stress in an organized manner."

"My mandala (see Figure 6) represents attempts to cope through enjoyable activities that I engage in to adapt to stressful situations and for stress reduction. My mandala is partially covered with a blue wave because I find this color 
and its symbolism of water to be calming. The other side of my mandala is covered with colorful musical notes because I often turn on music to cope, which uplifts my confidence and puts me in a cheerful mood. The five hearts represent each of my family members with whom I possess a close relationship. The lighter colors represent my younger family members because they remind me of my childhood and allow me to relive those memories. The larger and darker hearts represent my parents who guide me using their extensive personal experiences. The top corner of my mandala includes symbols that represent the value that I have for my culture and spirituality. I believe in God and praying helps me to cope because it brings peace to my mind and acts as a stress reliever. The bottom of my mandala encompasses nature and gym equipment/attire because working out, playing sports, and taking walks allow me to physically and mentally relax. As represented in my mandala, I use a positive approach to cope with stress and I have several internal and external support systems."

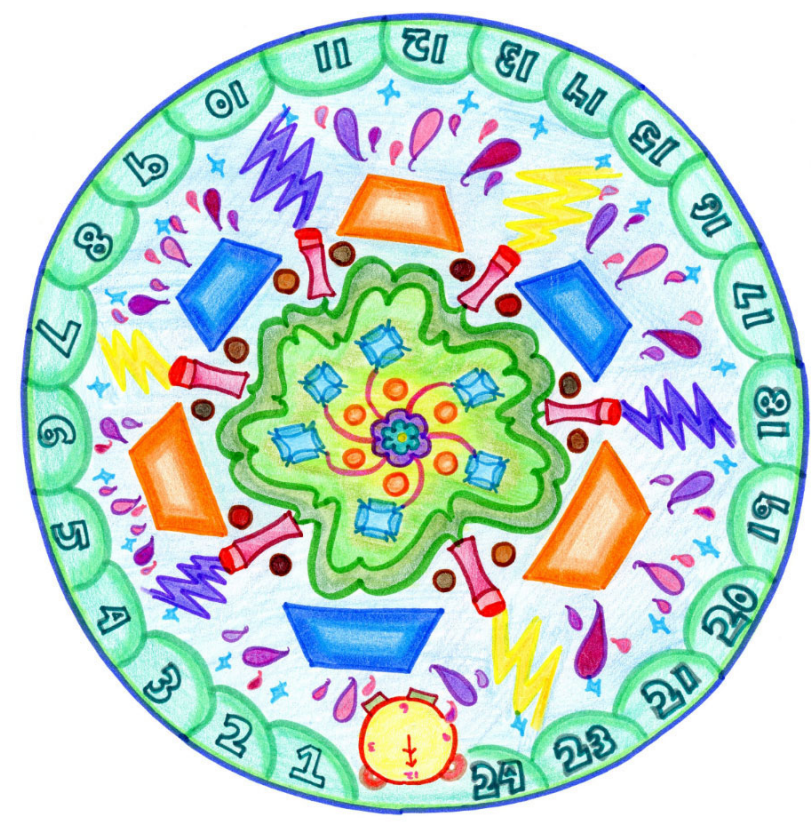

Figure 5. A driving force

\subsection{Student Four}

"My mandala of stress (see Figure 7) shows me sitting in my room alone and attempting to study for school exams. And yet, the thought bubble in my mandala reflects that all I could do at that moment was think about my hometown in Vietnam and the time I lived there years ago. As an international student studying in Canada, I do not have any close friends or relatives in this country and inevitably often feel alone. My main stressor is being isolated from my hometown and my family. Consequently, this reminiscence leads me to a desire for a visit to my hometown and my family so that my ongoing loneliness can be relieved. However, since travelling is not feasible during the school year, such desire becomes a constant stress that greatly affects my life. As illustrated in my mandala, even though my living environment is bright and vibrant like the red color in the background, everything in front of me appears to be coated with a sorrowful dark grey color."

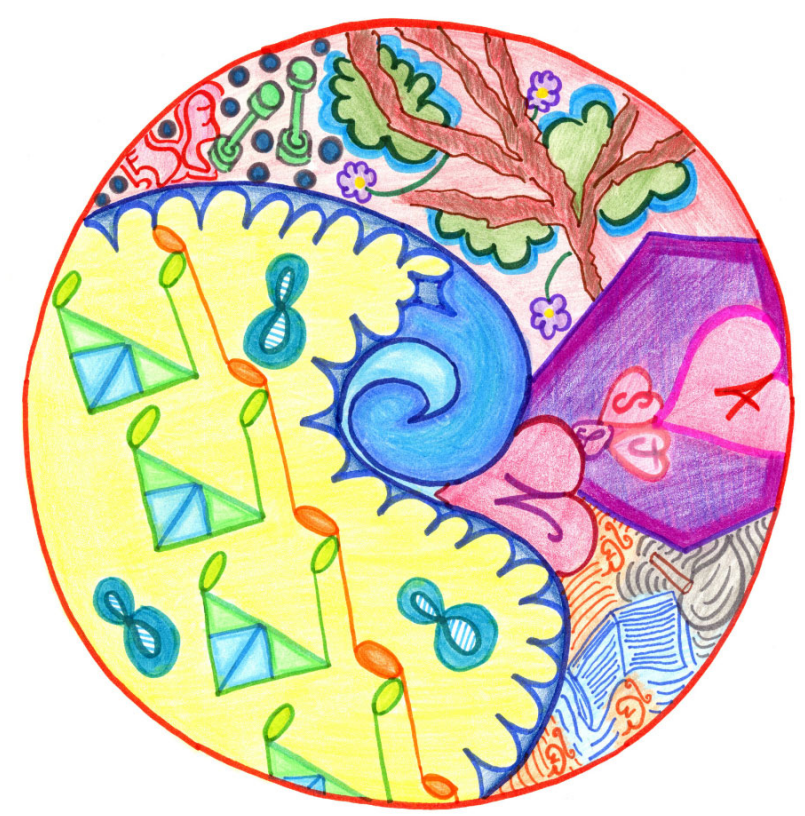

Figure 6. Support systems

"My coping mandala (see Figure 8) indicates a direct solution to relieve my stress, which involves travelling back to my home country during summer vacation. A landscape of my hometown in Vietnam is displayed in the mandala. My home is a small and quiet village nourished by a large river where most peoples' activities such as trading, transporting, and entertaining happen. The river also holds a lot of my childhood memories, for I have spent a great amount time swimming, fishing, and hanging out around it. Those vivid memories are the emotional bonds that I have with this place that together with the fresh and peaceful environment, make me feel calm and refreshed every time I think about and return to the village. Reminiscing about my childhood also delights and reminds me to search for internal peace for my mind and to rid myself of worries from the urban life in the city that I currently live."

\subsection{Student Five}

"My mandala (see Figure 9) was drawn to show how stress affects both my perception of reality and my mental state. My perception of reality is represented by the pink and red 
swirl, while my mental state is represented by the blue and black swirl. To illustrate the beginning of my narrative, the outside of my mandala is pink and blue to demonstrate my positive perception and my peaceful mindset, respectively. My experience of stress began when I discovered a golf-ball sized lump on my neck and was presented with the possibility of cancer. The dyad of my perception of reality and mental state was negatively impacted as the stress accumulated, and is depicted as the pink and blue swirls become red and black, respectively. The boldness of the red shows how my positive perception became grim and alarming with concerns for my health. The dark blue and black demonstrate that my peaceful mental state was eclipsed by feelings of loneliness, uncertainty, and despair. At the core of my mandala, the dark red sprawls outwards into the black to depict how my negative perception of the stressful event overwhelmed and diminished my mental state."

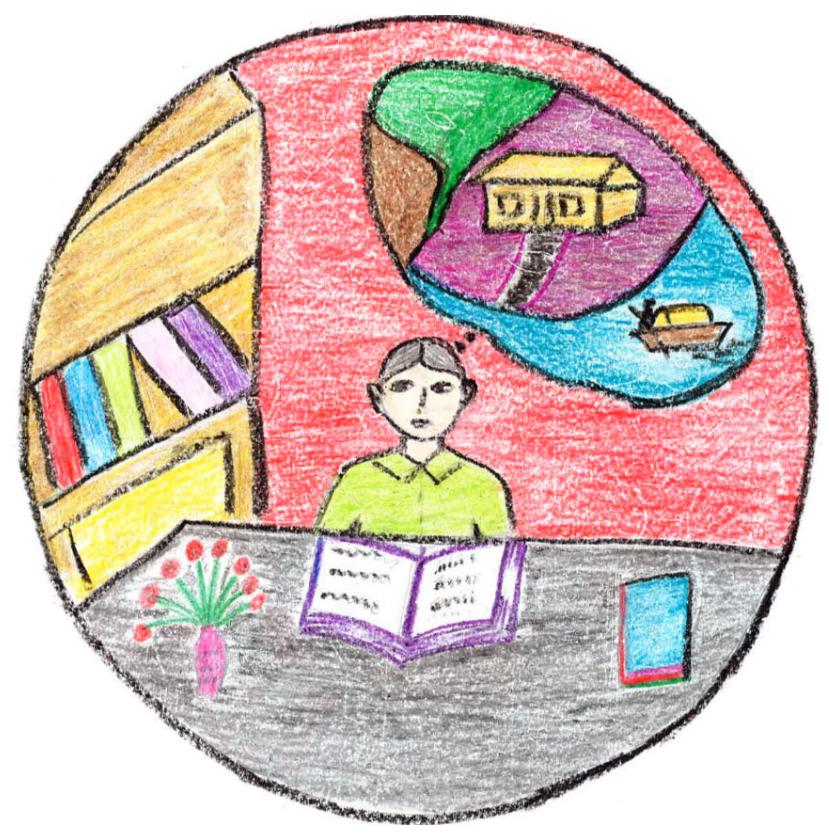

Figure 7. Isolation

"Similar to my stress mandala, my coping mandala (see Figure 10) has a dual swirl depicting my perception of reality and my mental state. Using the same color symbolism, the mandala swirls have alternating segments to show the effects of my coping attempts. My coping mandala begins on the outside with dark red and black-blue to show my grim perception of reality, and my despaired mental state, respectively. The swirl has segments of lighter colors depicting the stress-alleviating effects of my coping mechanisms such as visiting doctors, using distraction, and seeking social support. Similar to my stress mandala, the pink and blue colors demonstrate a positive perception and a peaceful mindset, respectively. As my medical ordeal resolved with no lifelimiting illness, the mandala swirls into a bright core with a pink heart to demonstrate the positivity and importance of social support in my experience of coping."

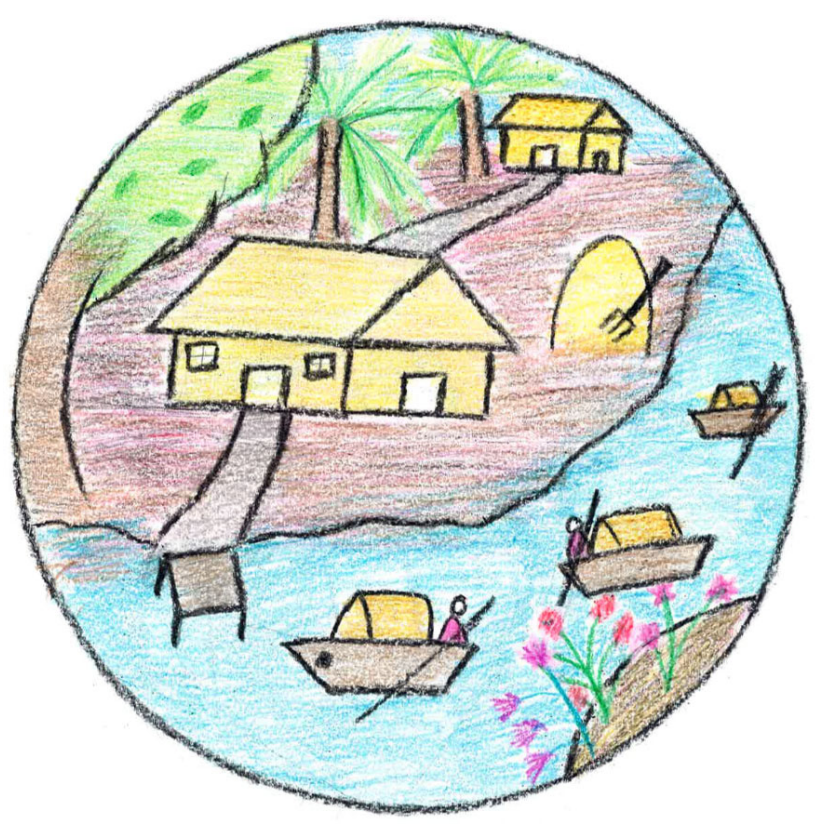

Figure 8. Travelling home

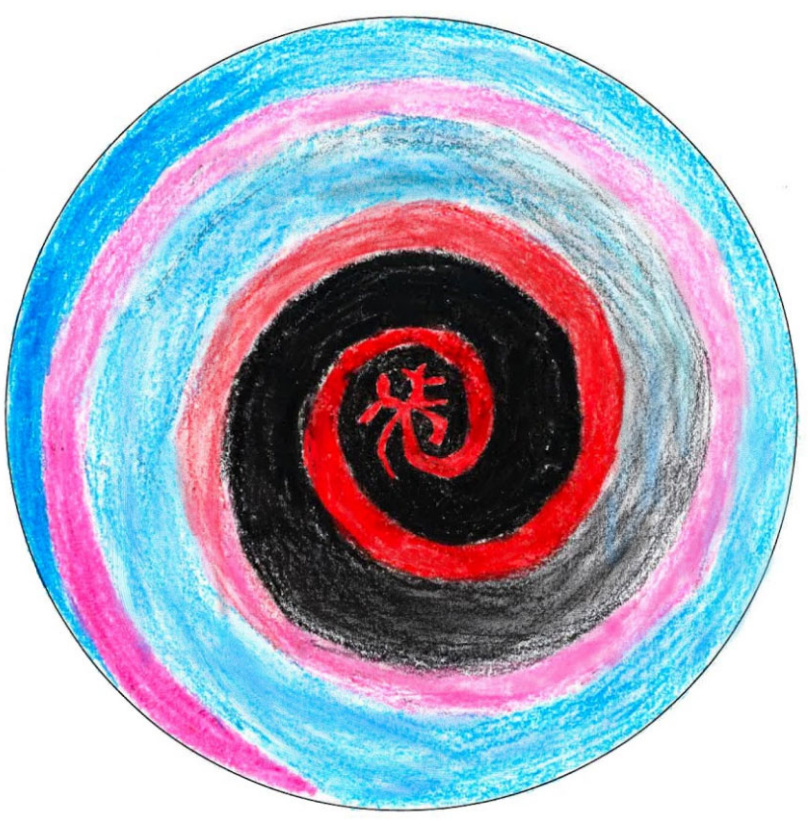

Figure 9. A golf-ball sized lump

\section{Discussion}

The pedagogy of mandala making coupled with narrative reflection acted as a creative way to facilitate learning about theoretical concepts specific to stress and coping. Students 
were able to recognize the material and concrete elements of theory that can be clinically applied; this is essential learning considering the abstract nature of theory. Others have used mandala making to assist students and practitioners to understand their own psychological state and depression care. ${ }^{[13,14]}$ We took this a step further by providing the opportunity for students to reflect on stress and coping while considering the conceptual literature. The writing and discussion that followed the mandala making was interwoven with elements of the literature. For example, students commented on how the activity guided them to holistically examine their experiences of stress and coping by identifying specific stimuli, processes, and responses; the writing prompts directed students to identify external stimuli such as sight and sound, to appraise the situation by identifying why it was stressful, and to reflect on stress responses by asking how they felt. Other students noted that mandala making facilitated a better understanding of the conceptual literature in terms of stress as dynamic ${ }^{[15]}$ and the coping mechanisms used by individuals that lend themselves to problem-focused or emotion-focused strategies. ${ }^{[16]}$ Students remarked that they were able to make sense of the conceptual literature by first applying it to their own lives and then, listening to their peers' narrative. This process allowed a broadening of perspectives on the significance of stress and various coping strategies. Future scholarship is required to examine whether students' interpretations within their mandalas were consistent with the conceptual literature within the curriculum content of the course.

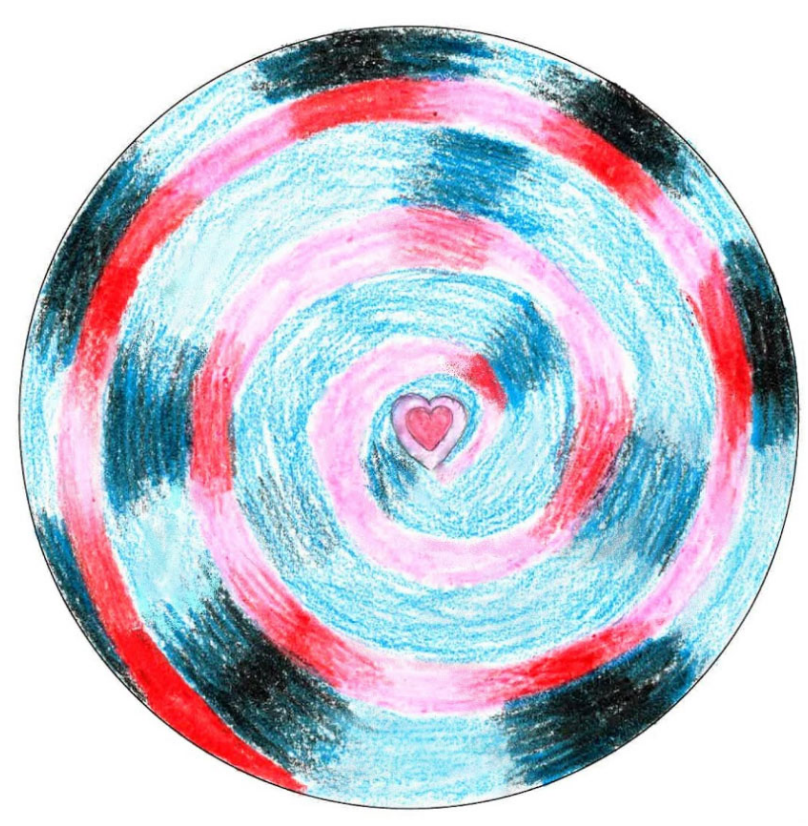

Figure 10. Coping
Our experience echoes existing literature in which visual methods, such as mandala making, can stimulate deep and intimate reflection. ${ }^{[9,13,17]}$ Reflection is a necessary first step to make sense of conceptual literature considering Parse's ${ }^{\text {[18] }}$ statement that "all phenomena have meaning only in light of beliefs and values" (p. 145). A visual approach can be a safe way for students to engage with a vulnerable topic as well as articulate something that may be ineffable. Although others have used group approaches to mandala making in nursing, ${ }^{[7]}$ students were asked to engage in the activity individually so that the mandala design was based on their own experiences and not influenced by their peers. Our work has extended the literature by identifying how aestheticallyinformed narrative probes further strengthened students' capacity for reflection and personal awareness. The aesthetic probes guided students to use all of their senses while reflecting and visually designing a mandala. Students remarked how the aesthetic probes prompted them to draw upon their emotions and think about their experiences holistically. Akin to aesthetic research approaches, ${ }^{[19]}$ our activity cultivated students' self-inquiry and reflection through a sensory and embodied experience that asked them to systematically consider the emotional tone of their mandalas, colors, and symbols. The dialogical approach that occurred after creation further stimulated students' reflections asking them to critically examine the symbols used and assess the origins, meanings, and implications to the understanding of the theoretical concepts of stress and coping.

Reflective learning offered through mandala making and narrative probing heightened students' sensitivity to other peoples' experiences of stress and coping. Like Palmer et al., ${ }^{[13]}$ we found that mandala making afforded opportunities to share and learn from one another. The dialogical approach encouraged students to consider another person's lived experiences, which may enhance empathetic behavior. Similar to Marshall, ${ }^{[7]}$ students involved in this activity felt that they not only developed self-awareness, but were positioned to more effectively recognize patients' and families' diverse and unique experiences of stress and coping. Students commented that listening to the story behind their peers' mandalas positioned them in a place where they could engage in an empathetic shift so they were more attuned to the lived experience of these theoretical concepts. Enveloping themselves in another person's narrative allowed them to see and feel another person's experience of stress and coping. Based on the mandala making activity, students remarked that they could recognize stress, empathize with clients, and be better positioned to co-design care plans to best reflect the patient's unique needs, wants, and goals - although this requires further evaluation. 
Mandala making did not require students to be artistic and those that were apprehensive could choose a more simple design based on their reflection. Similar to Palmer et al.' $\mathrm{s}^{[13]}$ work, students generally did not find mandala making difficult or onerous. Students remarked that the limited space of a circle aided them to stay focused on the theoretical concepts and prevented them from becoming flustered or going astray. Some students noticed that they were specific and deliberate in drawing whereas others reported drawing from an emotional place and choosing colors and a design based on their emotive reflections. Certain elements gained meaning as students began to add more detail as well as through the dialogue that followed. Often mandala making, like other art forms, can disclose elements of the subconscious making a person aware of something that was deeply concealed. ${ }^{[9]}$ Thus, the group discussion afterwards further facilitated students' insight into their own stress and coping as they were asked to speak to the mandala design. Although many students enjoyed the organic nature of mandala making, it was clear that the aesthetic narrative prompts expanded their reflections from a visual perspective and opened up the possibilities of how they thought about stress and coping. Whether mandala making could be used to facilitate students' understanding of other theoretical concepts might depend on the type of narrative told. We are left to ponder whether all stories can be exhibited in a visual form such as a mandala.

\section{Conclusion}

Mandala making as a pedagogical approach deepened students' reflections and introspection by providing a visual means to exhibit and further make sense of the theoretical concepts of stress and coping. The aesthetic narrative probes alongside the mandala making fortified students' capacity to explore the theoretical concepts from a sense-based and embodied perspective. The narrative and artistic reflections provided the opportunity for students to recognize the material within the abstract nature of theory.

\section{CONFlicts of InTEREST Disclosure}

The authorS declare that there is no conflict of interest.

\section{REFERENCES}

[1] Karnick P. The importance of defining theory in nursing: Is there a common denominator? Nursing Science Quarterly. 2013; 26(1): 29-30. PMid:23247345 https://doi.org/10.1177/08943184 12466747

[2] Yancey N. Why teach nursing theory? Nursing Science Quarterly. 2015; 28(4): 274-278. PMid:26396208 https://doi.org/10.1 $177 / 0894318415599234$

[3] Beuthin RE. Cultivating a narrative sensibility in nursing practice. Journal of Holistic Nursing. 2015; 33(1): 98-102. PMid:24904044 https://doi.org/10.1177/0898010114536633

[4] Lapum J, Hamzavi N, Veljkovic K, et al. A performative and poetical narrative of critical social theory in nursing education: An ending and threshold of social justice. Nursing Philosophy. 2012; 13(1): 27-45. PMid:22176546 https : //doi .org/10.1111/j.1466-769X . 20 $11.00520 . \mathrm{x}$

[5] Lapum J, Hume S. Teaching qualitative research: fostering student curiosity through an Arts-informed Pedagogy. The Qualitative Report. 2015; 20(8): 1220-1232.

[6] Lapum J, St-Amant O. Visual images in undergraduate nursing education. Nurse Educator. 2016; 41(3): 112-114. PMid:26402908 https://doi.org/10.1097/NNE.0000000000000214

[7] Marshall M. Creative learning: The mandala as teaching exercise. Journal of Nursing Education. 2003; 42(11): 517-519. PMid: 14626390

[8] Haidet P, Jarecke J, Adams E, et al. A guiding framework to maximise the power of the arts in medical education: A systematic review and metasynthesis. Medical Education. 2016; 50(3): 320-331. PMid:26896017 https://doi.org/10.1111/medu.12925

[9] Mahar D, Iwasiw CL, Evans M. The mandala: First-year undergraduate nursing students' learning experiences. International Journal of Nursing Education Scholarship. 2012; 9(1): 1-16. PMid:23241686 https://doi.org/10.1515/1548-923X.2313

Published by Sciedu Press
[10] McCormack B, McGowan B, McGonigle M, Goode D, Black P, Sinclair M. Exploring 'self' a person-centred academic through critical creativity: A case study of educators in a school of Nursing. International Practice Development Journal. 2014; 4(2): 1-18

[11] Jung CG. Mandala symbolism, 1972, Princeton University Press: Princeton, NJ.

[12] Stinley N, O'Norris D, Hinds P. Creating mandalas for the management of acute pain symptoms in pediatric patients. Art Therapy: Journal of the American Art Therapy Association. 2015; 32(2): 46-53. https://doi.org/10.1080/07421656.2015.1028871

[13] Palmer VJ, Dowrick C, Gunn JM. Mandalas as a visual research method for understanding primary care for depression. International Journal of Social Research Methodology. 2014; 17(5): 527-541. https://doi.org/10.1080/13645579.2013.796764

[14] Potash J, Chen J, Tsang J. Medical student mandala making for holistic well-being. Medical Humanities. 2016; 42(1): 17 25. PMid:26341101 https://doi.org/10.1136/medhum-201 5-010717

[15] Goodnite P. Stress: A concept analysis. Nursing Forum. 2014; 49(1): 71-74. PMid:24456555 https://doi .org/10.1111/nuf . 12044

[16] Dunn S, Conley Y. A systematic review on genetic influences on coping. Biological Research for Nursing. 2015; 17(1): 87-93. PMid:25504954 https://doi.org/10.1177/10998004145273 40

[17] Pisarik CT, Larson KR. Facilitating college students' authenticity and psychological well-being through the use of mandalas: An empirical study. Journal of Humanistic Counseling. 2011; 50(1): 84-97. https://doi.org/10.1002/j.2161-1939.2011.tb00108.x

[18] Parse RR. The Human Becoming Paradigm: A transformational worldview. Pittsburgh, PA: Discovery International; 2014.

[19] Lapum J, Liu L, Hume S, et al. Pictorial narrative mapping as a qualitative analytic technique. International Journal of Qualitative Methods. 2015; 14(5): 1-15. https://doi.org/10.1177/1609 406915621408 